\title{
Pattern separation, pattern completion, and new neuronal codes within a continuous CA3 map
}

\author{
Stefan Leutgeb ${ }^{1}$ and jill K. Leutgeb \\ Kavli Institute for Systems Neuroscience and Centre for the Biology of Memory, Norwegian University of Science and Technology, \\ N-7489 Trondheim, Norway
}

\begin{abstract}
The hippocampal CA3 subregion is critical for rapidly encoding new memories, which suggests that neuronal computations are implemented in its circuitry that cannot be performed elsewhere in the hippocampus or in the neocortex. Recording studies show that CA3 cells are bound to a large degree to a spatial coordinate system, while CAl cells can become more independent of a map-based mechanism and allow for a larger degree of arbitrary associations, also in the temporal domain. The mapping of CA3 onto a spatial coordinate system intuitively points to its role in spatial navigation but does not directly suggest how such a mechanism may support memory processing. Although bound to spatial coordinates, the CA3 network can rapidly alter its firing rate in response to novel sensory inputs and is thus not as strictly tied to spatial mapping as grid cells in the medial entorhinal cortex. Such rate coding within an otherwise stable spatial map can immediately incorporate new sensory inputs into the two-dimensional matrix of CA3, where they can be integrated with already stored information about each place. CA3 cell ensembles may thus support the fast acquisition of detailed memories by providing a locally continuous, but globally orthogonal representation, which can rapidly provide a new neuronal index when information is encountered for the first time. This information can be interpreted in CAl and other downstream cortical areas in the context of less spatially restricted information.
\end{abstract}

Theories about the possible function of CA3 in memory processing began with observations of its recurrent connectivity (Marr 1971; McNaughton and Morris 1987; Rolls 1989; Treves and Rolls 1991). Unlike most cells in other cortical regions, hippocampal CA3 cells are predominantly connected to themselves, and receive less than one-third of their inputs from other cell populations (Amaral et al. 1990). The most prominent source of external input to each CA3 cell is from cells in layer II of the entorhinal cortex (Witter 2007), while comparatively limited inputs are from other sources, such as from cholinergic and GABAergic cells in the medial septal area (Amaral and Kurz 1985), from interneurons in the CA1 area (Sik et al. 1994), and from a small number of dentate granule cells (Amaral et al. 1990). The dentate cells that project to each point in CA3 receive their inputs from largely the same entorhinal neuron population as the corresponding CA3 cells that receive the input directly (Witter and Amaral 2004). The prominent autoassociative projections between CA3 cells, along with backprojections to the dentate gyrus, will therefore reiteratively process highly convergent information from a select cortical input layer. Convergence in the layer II projections to CA3 is between the lateral and medial entorhinal cortex and also for different levels along the dorso-ventral axis in entorhinal cortex. Such a highly convergent system is in contrast to the parallel point-to-point projections between layer III of entorhinal cortex, CA1, and subiculum (Witter et al. 2000). Along with these prominent differences in the anatomical connections between the hippocampal CA3 and CA1 subregions, there are also pronounced differences in extracellular and intracellular oscillations in anesthetized and sleeping animals (Buzsaki et al. 1983; Csicsvari et al. 2000; Isomura et al. 2006; Hahn et al. 2007).

Considering these differences in connectivity and physiology of the CA3 subregion in comparison with the CA1 subregions, it is surprising that striking similarities in the firing char-

${ }^{1}$ Corresponding author.

E-mail stefan.leutgeb@ntnu.no; fax 47-73-59-82-94.

Article is online at http://www.learnmem.org/cgi/doi/10.1101//m.703907. acteristics of individual cells are found in behaving animals and that pronounced differences between the hippocampal subareas become only apparent when comparing their population dynamics (Barnes et al. 1990; Lee et al. 2004b; Leutgeb et al. 2004, 2007; Vazdarjanova and Guzowski 2004). To illustrate that these differences emerge only at the population level, we first present what is known about the electrophysiological activity of single CA3 cells in behaving animals, compared to corresponding data from the CA1 subregion. In the subsequent section, we then discuss how the activity of hippocampal cell populations is organized into maps. We first illustrate what has been found for CA1 cell ensembles (or in recordings that have not explicitly distinguished between CA1 and CA3) before presenting examples in which CA3 and CA1 have been found to be different. We argue that CA3 cell ensemble characteristics are consistent with completely distinguishing between two places and with making an additional distinction between related sensory configurations within each place. Although each of these two modes of processing corresponds roughly to pattern separation, they do not necessarily result in global attractor dynamics in CA3. Finally, we discuss how the neuronal activity patterns in CA3 could be consistent with functions that have been found for this subregion in behavioral studies and argue that the distinctive firing properties of CA3 cell populations rather than of single cells may support its role in the rapid acquisition of memories. We conclude that CA3 cell ensembles can support the fast acquisition of detailed memories by providing a locally continuous, but globally orthogonal representation that can rapidly integrate sensory inputs that are encountered for the first time into a previously learned framework.

\section{The electrophysiology of single CA3 cells in behaving animals}

Electrophysiological recordings in the different hippocampal subregions began before the discovery of place cells. In a series of studies, Olds and colleagues (Olds et al. 1972; Segal and Olds 
1972; Segal et al. 1972) devised approaches to search for the origin of learned responses by recording from single neurons. They reasoned that the site of learning in an appetitive conditioning paradigm would show the earliest responses in three different ways, that is, at the beginning of a brain pathway storing the information, immediately in time following the conditioned stimulus, and during the initial phases of training before the conditioned response emerged. Responses of cells in the CA3 subregion were consistent with the first two criteria, while cells in the CA1 subregion failed all three criteria. Although the third criterion was not met by CA3 cells, their neuronal responses appeared nonetheless briefly after the first indication of a behavioral response to the conditioned stimulus and briefly after dentate cells started responding. Although dentate cells started to respond early during training and early after stimulus onset, they also generalized their response to a second, nonreinforced stimulus and showed a later response component that was closely related to the animal's movement. Both of these properties therefore suggest that dentate cells were not specifically related to learning, but rather fired in direct association with the altered behavior. In contrast, neither the generalization to other stimuli nor the strict relation to the behavioral response was seen for either CA3 or CA1 cells (Segal et al. 1972). The activity of CA3 cells therefore seemed to partially match required criteria for learning-related neuronal firing, but similar and in many cases earlier learning responses were also seen in other brain areas, including the cortex and thalamus (Olds et al. 1972). Such a distributed increase in learning-related cellular activity in extrahippocampal areas can be expected in learning tasks that do not critically depend on hippocampal function. Similar parallel increases of cellular activity in multiple brain areas, including the hippocampus and amygdala (Segal et al. 1972; Berger et al. 1976; Berger and Thompson 1978; Stolar et al. 1989; Quirk et al. 1995; McEchron and Disterhoft 1997; Collins and Pare 2000; Munera et al. 2001; Repa et al. 2001), are also characteristic of aversive and classical conditioning paradigms, which also do not critically depend on hippocampal function.

In addition to not recording in tasks that require the hippocampus, these early studies also did not distinguish between principal neurons and interneurons within the hippocampus. The high average firing rates that were reported indicate that many of the recorded neurons may have been interneurons. Frequent movement correlates of hippocampal interneurons, along with orienting responses to stimuli and the execution of motor responses, therefore raised the criticism that many learning responses were, in fact, related to the appearance of response contingencies, as explicitly shown for dentate cells. The early studies were also done without keeping track of the animal's location (see O'Keefe and Nadel 1978). A possible interaction between the learning of a conditioned response and location-selective hippocampal firing has only been addressed recently when Moita et al. (2003) found increases in hippocampal responses to conditioned stimuli that are gated by the location-selective properties of the pyramidal cells. This suggests that the hippocampal learning of significant stimuli occurs in connection with a spatial map, at least in the CA1 area in which this possibility has been tested.

Differences in the firing of cells in the hippocampal CA3 and CA1 areas were not only suggested by the learning studies described above, but also in the early survey of Ranck (1973) on the firing properties of hippocampal interneurons and principal cells during incentive behavior. His description captured in essence the differences in firing of hippocampal cells between behavioral sequences and sleep and identified nonspatial firing correlates during awake behavior. Meanwhile, O'Keefe and Dostrovsky (1971) had discovered that the firing of many principal cells in the CA1 area occurred at restricted locations, often in a manner that was unrelated to other behavioral variables. Although there were convincing data for the spatial selectivity of CA1 cells, it was not known at the time when O'Keefe and Nadel (1978) published "The hippocampus as a cognitive map" whether these firing properties would also be seen in the CA3 subregion:

"We are now faced with two possibilities as the construction of the map. Either the map is constructed in the CA3 field and the CA1 field is primarily devoted to the misplace system, or the map itself is not constructed until CA1. On this latter view both the map and the misplace system are located in CA1; the CA3 field would then represent an intermediate stage between the compound-stimulus stage and the map of CA1. Part of the problem in deciding between these alternatives is our lack of information concerning the properties of CA3 approachconsummate units. Our examination of similar units in the CA1 field shows that they are true place units, continuing to respond when any stimulus is removed from our controlled environment (see pp. 205209). Ranck (1973) has reported that, while a minority of units in CA1 are approach-consummate units, they represent the majority of units in CA3. What is not known yet is whether the CA3 units are also place units." (O'Keefe and Nadel 1978, pp. 222-223)

Although still lacking data on the CA3 subregion, this description illustrates that they realized the importance of finding how the firing of upstream cells could give rise to the formation of place fields in CA1. They raised the possibility that cells that are highly selective for configurations of sensory inputs could first capture the various exact combination of sensory inputs from each viewpoint and that location-selective cells could then be constructed in the subsequent cell layer by combining the views that correspond to each location (O'Keefe and Nadel 1978). Such a mechanism can account for the selective firing of place cells to arbitrary configurations of sensory cues and, in combination with the discovery of a spatial map upstream of hippocampus (Hafting et al. 2005), also entail that each cell's response remains bound to selected spatial locations (Leutgeb et al. 2005b).

\section{Place fields in CA3}

Recordings from spatially selective CA3 cells were included in the report by Hill (1978), but without explicitly distinguishing between the hippocampal subareas. Other studies (Olton et al. 1978; Best and Ranck 1982) listed cases of recordings in CA3 and CA1 separately in their tables and provided the first evidence that spatial location was also the best descriptor for the firing of principal cells in the CA3 region. Spatial selectivity was subsequently also reported for dentate cells (McNaughton et al. 1983) and in hippocampal input and output regions (Barnes et al. 1990; Quirk et al. 1992; Leutgeb and Mizumori 2002; Fyhn et al. 2004). The evidence for location-selective firing of principal cells in all hippocampal subregions raised the question whether sequential processing first establishes fields in the dentate gyrus and CA3, which subsequently convey these firing properties to CA1 place fields or, alternatively, whether there are corresponding entorhinal projections to each subregion, which are transformed into place fields by similar processing algorithms within the dentate gyrus, CA3, and CA1.

Contrary to a sequential mode of processing, neither the dentate gyrus was found to be required for place fields in CA3 and CA1 (McNaughton et al. 1989) nor was CA3 found to be required for place fields in CA1 (Mizumori et al. 1989; Brun et al. 2002). These data were complemented by lesion and recording data of the entorhinal cortex (Miller and Best 1980; Barnes et al. 1990; Quirk et al. 1992) that suggested the presence of lowresolution spatial information outside of the hippocampus from which spatial information at a higher resolution could be derived 
independently by each hippocampal subregion. More definite evidence for spatial coding in the inputs to hippocampus was not found until the discovery of highly spatially selective cells in the dorsolateral part of the medial entorhinal cortex (Fyhn et al. 2004). Unlike place cells, which only fire at one or few locations in a recording apparatus, the medial entorhinal cells fire in a spatially repetitive, triangular grid-like pattern (Hafting et al. 2005). The presence of these cells in all layers of entorhinal cortex that project to hippocampus (Sargolini et al. 2006) further supports the possibility that place fields may be generated in parallel in the dentate gyrus, in CA3 and in CA1 (Fuhs and Touretzky 2006; Rolls et al. 2006; Solstad et al. 2006). Although such parallel mechanisms for generating place cells are likely, it remains unknown whether the presence of conjunctive "grid $\times$ head-direction" cells and head-direction cells in layer III of entorhinal cortex (Sargolini et al. 2006) and the preferred projections of this layer to CA1 (Witter et al. 2000; Witter 2007) require differences in the processing of the entorhinal information in hippocampus to result in largely corresponding firing properties between hippocampal place cells in CA3 and CA1.

The first comprehensive description of recordings from different hippocampal subregions can be found in Barnes et al. (1990), who compared place cells that were recorded on an 8-arm radial maze. The average and peak firing rates were similar in CA1 and in CA3, but with the rate distribution in CA3 more skewed toward zero and thus including a larger proportion of low rate cells. The data on a limited difference between CA1 and CA3 fields on the 8 -arm maze were complemented by quantitative comparisons between cells that were recorded in a cylinder (Muller et al. 1987). Again, no differences between the subregions were found except for an indication of higher firing rates within CA3 place fields, which may again reflect the skewed rate distribution for CA3 cells and that only those with robust average firing have identifiable fields in an open arena. These differences between CA1 and CA3 in the rate distribution as well as in the proportion of silent cells have been confirmed in recordings from large cell populations (Leutgeb et al. 2004) as well as in immediate-early gene labeling studies (Vazdarjanova and Guzowski 2004).

Along with not finding clear differences in place fields in an unchanged recording apparatus, many studies that explored how place cells in CA3 and CA1 respond to sensory or task manipulations failed to find differences. This was seen in the early reports that examined the firing of place cells in response to the rotation and the removal of cues (O'Keefe and Speakman 1987; Quirk et al. 1990) and in response to color changes of the cue card (Bostock et al. 1991) and was subsequently also reported for more complex cue manipulations (e.g., Tanila et al. 1997; Tanila 1999; Knierim 2002; Paz-Villagran et al. 2004, 2006; Renaudineau et al. 2007). Combining the recordings from both subregions was based on the findings that there are no apparent differences in how the cells respond to experimental manipulations. We will therefore first illustrate what has been found for CA1 cell ensembles (or in recordings that have not explicitly distinguished between CA1 and CA3) before mentioning a few examples where CA3 and CA1 have been found to be different. Particular emphasis will be given to the question how these spatially selective cells are organized into map-like representations.

\section{From spatially selective cells to maps}

Other than depicting either two- or three-dimensional space, maps may have few features in common. Even maps for approximately the same geographical location can contain essentially unrelated information, such as a winter map with cross-country ski trails and a summer map with hiking trails. Although differ- ent maps are not exchangeable with respect to their use in an inappropriate context, they relate to each other at shared points in space. The idea of the use of multiple maps by the brain, each for an intended purpose, has received intriguing support by the discovery of multiple maps for the same space in hippocampus (Muller and Kubie 1987), but also by evidence from other neural systems (e.g., Felleman and Van Essen 1991; Colby and Goldberg 1999).

For the hippocampus, Muller and Kubie (1987) found that a different set of place fields is activated when a black cylinder is replaced with a white one at the same location. In response to the manipulation, cells either turned on or off or changed their firing locations. To indicate that the same space is encoded with a different pattern of neuronal activity, they thought of different place fields and the altered relation between them as mapping the same space for a second time and called the phenomenon "remapping." In followup studies that introduced a barrier into the box, they found that cells close to the barrier would tend to remap, while those that are more distant would tend to remain unaffected. To distinguish the localized change around the barrier from the more global and complete change in different boxes, they introduced the concept of "partial remapping" as opposed to "complete remapping." Although "partial" was initially meant to indicate that a new map was formed for a subsection of the recording arena, the term was widely adopted to also describe incomplete changes in place fields in response to other manipulations of the enclosures and tasks. In many cases, remapping would not be restricted in space, but rather be restricted to a subset of the recorded place cells. The term "partial remapping" is thus also used for describing an incomplete or disconcordant response of place cells to experimental manipulations.

Although these experiments supported the notion that place cells can, in principle, remap after relatively minor changes in sensory cues as well as task contingencies, they were complemented by findings that suggested that place cell representations can also be cohesive and may not immediately respond to differences between cue configurations. Central to this notion is the occurrence of place fields as symmetrical fields without directional selectivity as well as their stability after cue removal (O'Keefe 1976; O'Keefe and Conway 1978; Muller et al. 1994), which directly suggests that multiple views are bound to an underlying spatial coordinate system. To assemble place cells, it would be sufficient to use the spatial coordinates only when first generating a map for a novel environment, but the use of pathintegration-based mechanisms for guiding hippocampal place cell firing continues after an animal has become well familiarized with its surroundings (O'Keefe 1976; Quirk et al. 1990). This has been shown convincingly in experiments, in which animals were trained to run back and forth on a linear track and were tested after shortening the track during subsequent trials (Gothard et al. 1996a, 2001). Although the place cell system reset to the visual cues after some distance, it initially used the start box behind the animal as a reference point. The anchoring of place field firing to an invisible reference point behind the animal thus suggested that the animal keeps track of distance by path integration after exiting the start box. In followup experiments, it was tested whether these findings extended to path integration in twodimensional arenas by testing whether animals could distinguish between two visually identical boxes that were placed next to each other and connected with an alleyway (Skaggs and McNaughton 1998). It was found that the boxes were partially distinguished, which suggested that neither the visual cues nor the path integrator could by itself control place field firing. One possible interpretation of these findings was that path integration contributed to place field firing in essentially the same way as 
other sensory cues and could thus gain partial control of the fields. However, a parallel study by Tanila (1999) suggested that a path-integration-based mechanism could completely distinguish between two boxes and that most cells would only be active in one or the other box, irrespective of the corresponding visual cues between the two boxes. In contrast to the earlier study that showed a partial effect of path integration and included only recordings from CA1, $88 \%$ of the recordings by Tanila were from CA3.

\section{Remapping in CA3 completely distinguishes between two separate locations}

When comparing place cell firing in the CA1 and CA3 subregions, we also recorded from visually similar boxes at two separate locations (Leutgeb et al. 2004). In our study, the animals were passively transported between recording locations, but with a clear view of the surrounding room layout in order to not compromise their ability to keep track of the change in location. Our studies showed that CA1 cells were often influenced by common features of the boxes, while simultaneously recorded CA3 cells distinguished completely between them (Fig. 1A). If CA1 cells respond to box similarity, then the prediction would be that they should show a more distinct response when minimizing shared elements between the enclosures. This was seen when recording in an enclosure of a different shape in yet another location. These data can therefore not only explain the different results between earlier studies in visually identical enclosures, but also show that responses to cue configurations are more common in CA1, while the CA3 subregion remains predominantly influenced by space and always completely distinguishes between two different locations (Fig. $1 \mathrm{~A}, \mathrm{~B})$. Using randomization procedures, it can be shown that two CA3 cell populations that are active in two separate places overlap to exactly the extent that would be expected by randomly selecting a new set of active cells. A mechanism that activates new cells at a different location in space and is rather independent of cue configurations in the environment can not only activate decorrelated sets of cells in two different rooms, but already when an animal has moved outside of the radius of an average place field in dorsal hippocampus, which is $\sim 30 \mathrm{~cm}$ in rats (Maurer et al. 2005).

Such a path-integration-based mechanism of distinguishing two locations has recently been shown to be tightly correlated with selecting a different spatial map upstream of the hippocampus, in the superficial layers of the medial entorhinal cortex. In a second room, grid cells are always shifted with respect to the
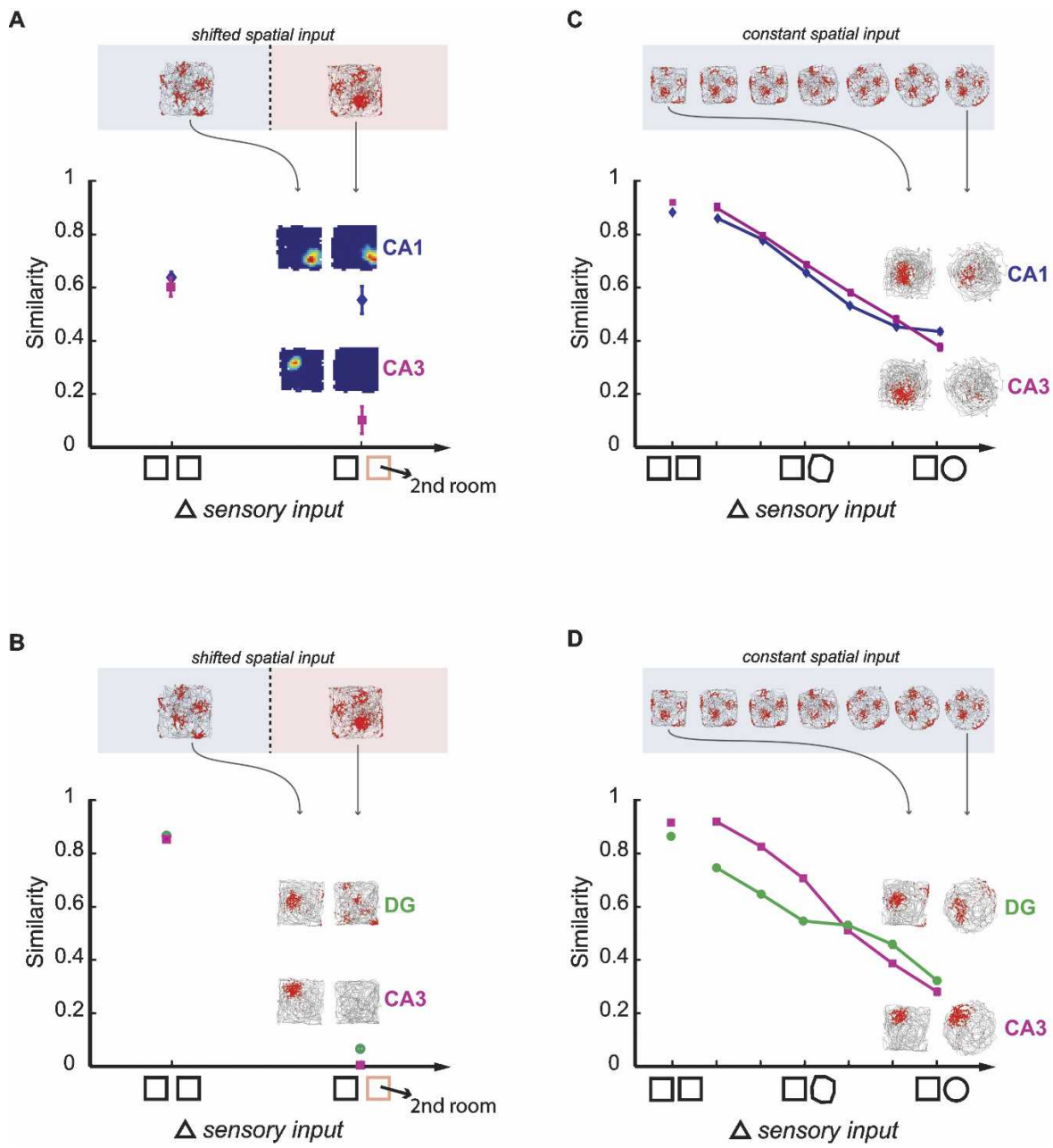

Figure 1. Pattern separation and pattern completion processes in CA3 are bound to spatial coordinates. The comparisons on the left of each plot $(\square \square)$ indicate the level of similarity that is seen for repeated recordings in identical square boxes. The similarity is measured by comparing $(A)$ rate vectors or $(B-D)$ population vectors between recordings (see Leutgeb et al. 2004, 2005a, 2007). The comparisons to the right of each plot are $(A, B)$ for recordings in separate rooms or $(C, D)$ for recordings with gradually increasing differences in sensory inputs at fixed room coordinates. Each top panel shows recordings from a grid cell in the same behavioral paradigm. The arrows indicate that the spatial inputs from these cells to the hippocampus are either shifted or fixed. The maps within each plot show the firing of $(A, C)$ simultaneously recorded $C A 1$ and $C A 3$ cells or $(B, D)$ simultaneously recorded dentate and with pixels that are not visited in white. The spikes (red dots) from each cell are superimposed on the rat's trajectory (gray) in $B-D$. Note that each of the three hippocampal subregions shows a different type of response in the second room. Dentate cells remain active in both rooms, but show entirely unrelated spatial firing patterns, while CA3 cells are typically only active in one or the other room. In CA1, many cells continue to code for similarities between the boxes. In contrast, related response patterns are observed when sensory inputs are changed within a single spatial reference frame. Here, dentate, CA3, and CA1 cells showed robust rate remapping while their firing locations remained unchanged. The data are adapted from Leutgeb et al. (2004, 2005a, 2007). The dentate cell and CA3 cell in $B$ and $D$ are identical.

walls of the enclosure and often also rotated (Fyhn et al. 2007). These altered patterns of grid cell firing would then result in activating a different set of place cells. For example, a different output at each location could be obtained directly from the summation of grids with different spatial frequencies. Such a mechanism would again not only explain how different sets of cells get activated in two different rooms, but could also account for the completely different sets of active place cells at shorter distances (Solstad et al. 2006). The minimum possible decorrelation would occur at the distance of the smallest grid spacing, which is, like the size of place fields, $\sim 30 \mathrm{~cm}$ in the rat (Hafting et al. 2005). 
Can shifts of entorhinal grid cells also account for remapping, when the majority of simultaneously recorded cells changes at a single location (e.g., Bostock et al. 1991; Kentros et al. 1998; Wills et al. 2005)? Under these circumstances, it is possible that remapping involves the same form of network dynamics as when rats are moved between spatial locations. When complete remapping occurs at a constant location, the animals could reset their path integrator in the medial entorhinal cortex to a prominent landmark and would then use a coordinate system with a different origin for the same real-world coordinates. In an experiment that tested animals in two different enclosures at the same location, such resetting occurred each time the animal was shifted between the two boxes and resulted in a corresponding shift in the firing peaks of the medial entorhinal cortex grid cells (Fyhn et al. 2007). The defining characteristic for global remapping is therefore not necessarily whether it occurs in a single place or in different places, but whether the spatial inputs to the hippocampus have changed.

However, remapping would in those cases only be complete in CA3, while similarities in place fields remain for those CA1 cells that are strongly bound to sensory features in each of the two enclosures. Such pronounced binding of CA1 cells to arbitrary configurations would result in the incomplete separation of two recording arenas as long as they share common elements (Skaggs and McNaughton 1998; Leutgeb et al. 2004). Furthermore, it would also be consistent with the result that adding cues to a linear track can result in a higher incidence of bidirectional firing fields. The CA1 cells would be bound to a path-integrationbased map in one direction, but also be activated by the local cues irrespective of the running direction (Battaglia et al. 2004). Although such a mechanism may explain the place field dynamics in this experimental paradigm, a complementary mechanism could give a similar result. The same map could be used irrespective of the running direction, and the firing rates within the fields would be modulated by differences in the local view when approaching the same location from opposite directions (e.g., Hollup et al. 2001). The second mechanism is described in more detail in the following section.

\section{A second form of "remapping" occurs within a coordinate system}

Assuming that global remapping is a process that corresponds to moving between different locations and thus uses different inputs from the spatial map in the entorhinal cortex implies that the spatial map is retained as long as the animal remains oriented in space. In accordance with such a mechanism, it was found that medial entorhinal grid cells showed unchanged firing patterns (Fyhn et al. 2007; Leutgeb et al. 2007) and that most place fields in CA3 and CA1 retained their firing location when animals were tested in a task that altered visual cues without ambiguity about the animals' current location (Leutgeb et al. 2005a,b). In such paradigms, rate changes at retained firing locations are pronounced in CA3, but can also be seen in recordings from CA1 and dentate cell populations (Fig. 1C,D) (O'Keefe and Speakman 1987; Tanila et al. 1997; Leutgeb et al. 2005b, 2007; Hargreaves et al. 2007). Although rate rather than location changes of place fields may sometimes appear as a less pronounced form of remapping (Lever et al. 2002; Hayman et al. 2003), we found that the expression of rate coding can be particularly robust in CA3, where the rate changes often result in $>10$-fold differences in peak firing rates within the place field (Leutgeb et al. 2005b). Such rate remapping can result in differences in hippocampal population coding that reaches approximately the same degree of dissimilarity as observed with global remapping, and it is the predominant form of recoding within a single spatial reference frame (O'Keefe and Speakman 1987; Hayman et al. 2003; Leutgeb et al. 2005b). Having a dedicated encoding mechanism for space upstream of the hippocampus and transforming it into a sparsely active cell sheet with random spacing between place cells allows for setting up a spatial matrix in CA3 to which additional nonspatial information can be bound. In this coding scheme, the place code can be independent of the rate code, very much in analogy to sensory cortices, such as the primary visual cortex in which the identity of a neuron indicates where the stimulus has been placed and in which the firing rate indicates other attributes, such as the orientation or the contrast.

\section{Two forms of partial remapping}

Distinguishing two forms of remapping also implies that partial remapping in CA1 can have two different underlying mechanisms. When the spatial inputs to hippocampus are different, the retained fields correspond to those that are strongly bound to sensory cues. When the spatial inputs remain the same, the retained fields are those that respond the least to nonspatial inputs. The difference between these forms of partial remapping may not be obvious when recording few hippocampal cells, but can be seen in the statistical analysis of larger hippocampal cell populations (Tanila et al. 1997; Leutgeb et al. 2005b, 2006a, 2007; Hargreaves et al. 2007). Such an analysis with reference to the animals' coordinates is feasible if a valid assumption about the path-integrator coordinates can be made (Fig. 2). This can either be done by realigning the recorded cells to the apparatus boundaries at the time of data analysis or, more convincingly, by simultaneously recording from extrahippocampal components of the spatial map, such as head-direction cells and grid cells (Fyhn et al. 2007; Hargreaves et al. 2007; Lipton et al. 2007). In contrast, location shifts of place cells are not necessarily indicative of the type of remapping. A substantially decreased firing rate in one field along with an increased firing rate in the other could give rise to an apparent shift in the firing location (Fig. 2E). Because CA1 cells are more likely to have two fields (e.g., Leutgeb et al. 2004), it is more difficult to distinguish rate and global remapping in this subfield. We have frequently observed that rate remapping can suppress the firing to such an extent that the remaining firing field has peak rates below $1 \mathrm{~Hz}$, with few remaining spikes occurring at the same place as the much more pronounced field (Figs. 1 and 2; see also Leutgeb et al. 2005b).

The importance of distinguishing between the different modes of remapping that normally occur either at a constant location or at two different locations has previously been recognized for recordings from aged animals (Barnes et al. 1997; Tanila et al. 1997; Rapp 1998). When returning to a familiar room where the same spatial coordinates should be used, aged animals show a tendency to use a completely unrelated map (Barnes et al. 1997). In contrast, when tested in two different rooms, the older animals tended to reuse a previously learned map (Wilson et al. 2004). Such a propensity to inappropriately apply a pre-formed map to a different context is particularly pronounced in CA3, while CA1 cells respond to altered sensory cues to approximately the same extent as those of young animals (Wilson et al. 2005). These findings therefore suggest that the binding of the CA1 cells to sensory cues is relatively normal in the aged hippocampus, but that the mechanism for retrieving the appropriate map for each enclosure is impaired.

The stronger binding of CA1 cells to sets of sensory cues suggests that its place cells are not strictly organized into a single spatial map, but that there are multiple related maps, each encoding a different subset of the total spatial and nonspatial information and overlapping at common nodes (Eichenbaum et al. 
A

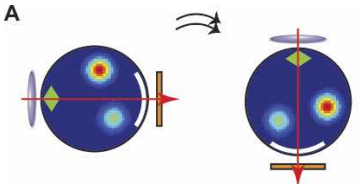

B

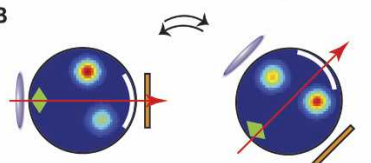

C
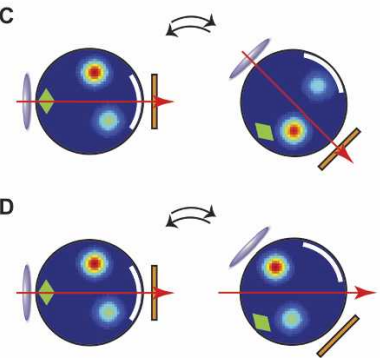

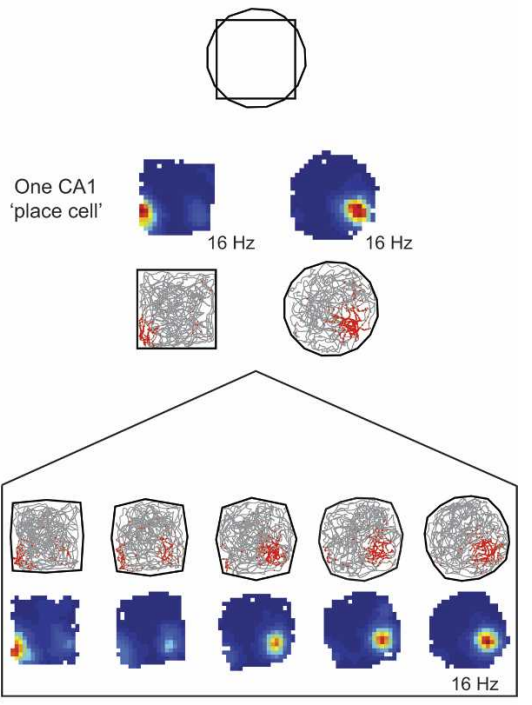

Figure 2. Distinguishing between continued place field firing within a fixed coordinate system and direct responses to cue configurations requires that the currently used coordinate system is known (see text for details). Illustrations of possible changes in place field firing after sets of sensory cues are rotated. $(A)$ In concordant rotations, all place fields remain aligned with the cues and with the headdirection system (indicated by the red arrow). ( $B, C)$ When the two sets of cues are rotated into conflicting orientations, place cells can be observed to predominantly rotate with the set of cues that also remains bound to the head-direction system (Hargreaves et al. 2007). Along with the rotation, place fields can be expected to either decrease or increase their firing rate in response to the changed cue configuration. (D) An incoherent response would be seen for place fields that are controlled independently of the head-direction system. This is more frequently observed for CA1 cells, which are not as tightly bound to an underlying coordinate system as CA3 cells. Grid cells in the entorhinal cortex are part of the spatial map and may follow similar rules as head-direction cells (Hafting et al. 2005; Sargolini et al. 2006). (E) Gradual changes in box geometry can also indicate whether changes in place field firing occur within a fixed coordinate system. An example of place-specific firing of one representative CA1 cell is shown for a sequence of 10-min recordings in a morph box that is first presented as a square enclosure, and then changed to a circular enclosure through a series of five intermediate shapes. Color-coded rate maps and trajectories with spike locations are shown as described for Figure 1. There is a location shift in firing between the recordings in the square and circular enclosures. The type of remapping between the enclosures becomes evident in the transition through intermediate box shapes (shown in the lower panel). Each field shows changes in rate without corresponding location changes ("rate remapping"). The decreased firing rate in one field along with an increased firing rate in the other can then appear as if the field had shifted its location. A corresponding pattern of increasing and decreasing firing rates is also seen for multipeaked cells in the dentate gyrus (see Fig. 2 in Leutgeb et al. 2007).

1999). Such an interpretation is further supported by the finding that CA1 fields can not only be bound to sensory stimuli within one modality (i.e., visual), but also to stimuli of several different modalities with each modality having a variable and experiencedependent weight in controlling each place field (Bostock et al. 1991; Knierim et al. 1995; Gothard et al. 1996b; Shapiro et al. 1997; Jeffery 1998; Wood et al. 1999; Lever et al. 2002; Anderson and Jeffery 2003). The rather arbitrary responses of CA1 cells to contextual manipulations are in contrast to the more coherent responses of CA3 cells to follow one set of cues (Shapiro et al. 1997; Lee et al. 2004b; Leutgeb et al. 2004; Vazdarjanova and Guzowski 2004). Unlike the memory space in CA1 (Eichenbaum et al. 1999), the CA3 network is therefore more constrained to a single map and remains bound to a fixed coordinate system upstream of the hippocampus (Leutgeb et al. 2005b, 2007; Fyhn et al. 2007).

\section{Is a distinction between two forms of remapping relevant for learning and memory?}

In parallel to the two different forms of remapping, learning tasks can be classified as those that require memory for a new location and those that involve the acquisition of new information at a well-familiarized location. Although this distinction can often be made by directly referring to experimental procedures, there are many instances when two maps are used for a single location or when a single map is reused for the same apparatus in a second place. The extent and the nature of remapping in memory tasks can therefore only be inferred by directly recording from ensembles of place cells (O'Keefe and Speakman 1987; Wood et al. 2000; Nakazawa et al. 2002; Ferbinteanu and Shapiro 2003; Smith and Mizumori 2006a; Griffin et al. 2007) or from other cell types that are associated with the spatial map (Lipton et al. 2007). These studies often found trial-unique spatial firing along the trajectory to the goal, which may be indicative of the sequence that is required to reach the goal (Wood et al. 2000; Ferbinteanu and Shapiro 2003) or as setting the context for the task requirement (Jeffery et al. 2003; Smith and Mizumori 2006a; Griffin et al. 2007). If providing information about the path to a goal, remapping should at least partially preserve information about places and, in particular, about relevant locations within the spatial coordinate system, such as choice points and goal locations (e.g., Eichenbaum et al. 1987; Otto and Eichenbaum 1992; Fyhn et al. 2002; Knierim 2004). Performance may thus be best supported by rate remapping within a fixed coordinate system. In contrast, when hippocampal place cells are merely required to set the context, but do not directly store information about either the journey or the goal, they could completely switch to an unrelated map (Jeffery et al. 2003; Anderson et al. 2006; Smith and Mizumori 2006b), and performance may thus be better supported by global remapping. Studies that have addressed remapping in CA3 or coordinate shifts in entorhinal cortex during the performance of these different types of memory tasks are not yet available to address whether such a distinction exists. In a series of studies that explicitly distinguished CA3 and CA1 cells (Hampson et al. 1993, 1999), the analysis focused on differential responses for task-relevant events, and, as for the early studies that identified learning responses in hippocampus (Olds et al. 1972; Segal and Olds 1972; Segal et al. 1972), it remains unknown how these responses are integrated with the spatial firing properties that can also be expected in the same cell populations.

\section{Pattern completion within a fixed coordinate system as a mechanism for memory retrieval and for retaining the current map}

A striking stability of place fields is seen when removing a subset of cues, at least as long as the remaining information does not allow for ambiguity about the animal's current spatial location. Although some rate changes or the loss and gain of individual 
fields can occur with an incomplete set of cues, the majority of the fields remain in place. Along with the stability of the fields, the animals' behavioral responses continue to be accurate (O'Keefe and Speakman 1987; Nakazawa et al. 2002). The unresponsiveness of place cells to an impoverished sensory input can be attributed to short-term memory for previously presented cues or to the retrieval of the complete information from long-term memory by pattern completion. Both of these processes can be implemented in recurrent network architectures and, although the recordings were taken from CA1, have thus been proposed to be performed by the intrinsic connectivity of the CA3 subregion (Marr 1971). This notion has received convincing experimental support in mice with a selective CA3 NMDA-receptor knockout (Nakazawa et al. 2002). The animals without receptor function in CA3 retained neither stable place fields nor the memory for a goal location in the presence of an incomplete set of cues. Retrieving a complete map within a fixed coordinate system therefore requires synaptic plasticity in CA3.

As in experiments with partially removed cues, relatively minor changes in place field firing are also seen when coherently manipulating the majority of available sensory cues, such as in cue rotation experiments (O'Keefe and Conway 1978; Muller and Kubie 1987; Bostock et al. 1991). As expected, most place fields stay aligned with the cues (Fig. 2A), and altered fields are only seen to a somewhat higher extent as in repeated recordings with stable cues. In corresponding experiments, coherent rotations are also seen for head-direction cells (Taube et al. 1990), headdirection cell and CA1 ensembles (Knierim et al. 1995), as well as grid cells and conjunctive "grid $\times$ head-direction" cells in the entorhinal cortex (Sargolini et al. 2006). Although minor variations of hippocampal place fields can be observed in these experiments for cells that seem to be controlled by static background cues that inevitably become conflicting (e.g., O'Keefe and Speakman 1987), such responses become much more frequent when sensory cues are rotated into an explicitly conflicting arrangement (Shapiro et al. 1997; Tanila et al. 1997; Knierim et al. 1998; Fenton et al. 2000). For example, when one set of cues is rotated clockwise around the center of a track or recording arena and a second set of cues is rotated counterclockwise, most fields rotate either with one or the other set of cues, completely disappear, or rapidly emerge (Fig. 2B-D).

Even with conflicting rotation angles between different sets of cues, the head-direction system has been shown to always stay coherent with one of the sets (Yoganarasimha et al. 2006). Furthermore, spatially selective cells in parahippocampal cortices, including the entorhinal cortex, remain bound to the headdirection system (Sargolini et al. 2006; Hargreaves et al. 2007). In the same experimental paradigm, most CA1 cells rotate with either one or the other set of cues, while others change in an entirely unrelated way. Although a split is observed for the CA1 cells, it can nonetheless be shown that the majority remain bound to the rotation of the head-direction system (Knierim et al. 1995; Hargreaves et al. 2007). Similar results can be obtained when the recording apparatus is not rotated, but shifted to a different location (Yoganarasimha and Knierim 2005) or even when it is shifted and rotated (Dudchenko and Zinyuk 2005). Both the head-direction and the place-cell system have then been shown to remain aligned with the apparatus rather than bound to a room-based coordinate system (O'Keefe and Speakman 1987; Dudchenko and Zinyuk 2005; Yoganarasimha and Knierim 2005). By resetting the spatial reference to the recording apparatus, the animal would keep its own coordinates aligned with the box, but the configuration of distal cues would be seen in a different way from each place. Rate remapping would now occur as if the animals were in the previous location (Fig. 2B), but now in response to different distal cue configurations ( $\mathrm{O}^{\prime}$ Keefe and
Speakman 1987; Hayman et al. 2003; Vazdarjanova and Guzowski 2004; Yoganarasimha and Knierim 2005).

Compared to CA1 cells, CA3 cells show a larger degree of coherence with disconcordant cue manipulations (Lee et al. 2004b) and therefore likely remain bound to the same underlying coordinate system as most CA1 cells. These results also indicate that the absence of recurrent connectivity in CA1 results in more diverse responses of place cells in this subregion, while CA3 cells retain their spatial relationship and can be said to pattern complete to remain bound to a single set of coordinates. In recordings in a circular arena (rather than on a circular track) in a similar experimental paradigm, the coherence of CA3 cells has been less clear (Renaudineau et al. 2007). However, it is not known to what extent the effect was restricted to CA1 cells in the sample and if larger ensembles of only CA3 cells would have shown the more coherent responses that were reported in previous studies. Although CA3 cell ensembles often remain strongly bound to a single map-like representation (Leutgeb et al. 2005b; Fyhn et al. 2007), a limited degree of incoherence is possible with strongly disconcordant cues (Lee et al. 2004b).

The finding that place fields can remain predominantly bound to a single spatial reference frame also extends to experiments in which shifted box walls result in either smaller or larger rectangular and square boxes (O'Keefe and Burgess 1996). Here it is found that CA1 place fields can either split to be controlled by each of two displaced walls or that they can stretch to approximately the same extent as the increase in the distance between the walls. Although it was at first unclear how such geometrical changes in place fields could go along with the constant grid spacing that had been reported for recordings in boxes of different sizes (Hafting et al. 2005), it was found that the initially reported size invariance in spacing does not apply to all experimental paradigms. For example, box resizing can result in shrinking or stretching of the grid spacing, in particular when the animals are not well familiarized with each of the boxes (Barry et al. 2007). Such geometric transformations can occur independently for the $X$ - and $Y$-axes of a quadratic box, and they seem to follow largely the same rules as those that were previously observed for hippocampal place cells in the same experimental paradigm. The only apparent difference between grid cells and place cells is that place cells respond with much more pronounced rate differences to the manipulations (O'Keefe and Burgess 1996; Barry et al. 2007), thus confirming our observation that intrahippocampal rate changes are the predominant form of encoding cue configurations when the spatial coordinate system remained in place (Leutgeb et al. 2005b). This effect after resizing boxes has only been reported for CA1 cells (O'Keefe and Burgess 1996), but likely also applies to CA3, where cells are more strongly bound to spatial coordinates and show larger rate changes (Leutgeb et al. 2005b; Fyhn et al. 2007).

Taken together, these observations suggest that global remapping and rate remapping reflect different neuronal computations, with different forms of intrahippocampal and parahippocampal contributions (Leutgeb et al. 2006b, 2007; Fyhn et al. 2007). A fast and coherent shift in entorhinal firing fields during global remapping (Fyhn et al. 2007) may provide sufficiently different direct inputs to the hippocampus to activate different cell ensembles with different place fields. The expression of new place fields might in such cases not require much further processing within the hippocampus, and an entirely unrelated subpopulation of CA3 cells might automatically be activated at a second location (Leutgeb et al. 2004, 2007; Fyhn et al. 2007).

\section{Pattern separation in spatial maps}

Along with realizing that path integration is, in appropriate conditions, the predominant influence on place cell firing (Knierim 
et al. 1995; Gothard et al. 1996a), McNaughton and colleagues (McNaughton et al. 1996; Samsonovich and McNaughton 1997) recognized that this would best be implemented in attractor networks with recurrent connections. An attractor is a stable network state that can, in principle, be obtained in several network architectures, with different training protocols, and in various brain regions (Amit 1989; Rolls 1989; Treves and Rolls 1992; Skaggs et al. 1995; Samsonovich and McNaughton 1997; Tsodyks 1999; Freedman et al. 2003; Blumenfeld et al. 2006; McNaughton et al. 2006). Among the simplest solutions for implementing attractor dynamics is in a cell population with dense recurrent connections that project directly back to cells in the population where they originated (Marr 1971). Within this larger population, a subpopulation of active cells that is strongly connected to each other can then sustain its own activity. If these cells are arranged on a hypothetical two-dimensional sheet according to their connection strengths, so that cells with nearby place fields and connected more strongly become neighbors, it is possible to move the cells' activity smoothly along a path (Samsonovich and McNaughton 1997). External input in the proximity of the currently active region can distort and shift the activity in the network, but an abrupt transition to a different set of active cells can only occur when external inputs have a competitive advantage over the currently active internal connections. Such continuous or "line" attractors are different from discrete attractors with local minima, which can be used for memory retrieval by moving toward a pre-formed representation after being presented with partial cues (Marr 1971; Amit 1989; Rolls 1989; Treves and Rolls 1991). Although advantageous for retrieving memories, such discrete states would not well support a path-integration-based mechanism, in which the activity should not drift to neighboring network states in the absence of inputs that indicate a translocation in space. One solution to resolve this incompatibility between network states for path integration and for memories is to allow path integration in multiple charts, with each chart being activated when retrieving memories for a particular context (McNaughton et al. 1996; Samsonovich and McNaughton 1997; Battaglia and Treves 1998). A further possibility is that these two functions are allocated to different cell populations. Several key components for attractor-based path integration exist in the entorhinal cortex, upstream of the CA3 area (Hafting et al. 2005; McNaughton et al. 2006). CA3 would thus not make a primary contribution to either path integration or spatial mapping, but rather more indirectly contribute to computing spatial position within the entorhinal cortex, for example, by joining discontinuities (Wallenstein et al. 1998) and by storing associations between different maps (Witter and Moser 2006).

Such a rather indirect role of CA3 for spatial processing would imply that CA3 is tied to spatial processing only to more effectively perform its role in memory processing. Grid cells in layer II do not show directional selectivity (Hafting et al. 2005; Sargolini et al. 2006) and therefore encode two-dimensional space without biasing the network toward moving into neighboring activity states. The symmetrical inputs from layer II, along with the strong recurrent connectivity in CA3, could thus result in CA3 place fields that have a strong propensity to keep their position within the map and to attach sensory cues or "events" to a single spatial coordinate system.

A map would therefore not be constructed in CA3 by combining different movement paths (Brunel and Trullier 1998; Kali and Dayan 2000; Buzsaki 2005), but conversely, would have an important influence on distinguishing different behavioral episodes. Although such a representation of the environment is not egocentric or self-centered, it keeps nonetheless track of the continuous relocation during movement and organizes the continuous flow of information in space, and when taking a path through a series of spatial locations, also in time. Such a relation between a spatial mapping system and a memory system has been recognized previously as automatically generating an index for memories (McNaughton et al. 1996). This suggestion is strengthened by the finding that two levels of pattern separation are expressed in the CA3 network. A completely orthogonal subset of cells is active at different locations (Leutgeb et al. 2004). At the same location, the retained spatial firing of CA3 cells would appear to pattern complete, but the cell population's firing can, in turn, be diversified by using different rate distributions for each set of sensory cues that is encountered at a place (Leutgeb et al. 2006b).

Even though three key ingredients for attractor dynamics, pattern separation, pattern completion, and recurrent projections are found in the CA3 subregion (Marr 1971; McNaughton and Morris 1987; Lee et al. 2004b; Leutgeb et al. 2004; Vazdarjanova and Guzowski 2004), there is no definite evidence that attractor dynamics in the CA3 network are used to distinguish between two sets of sensory cues. One characteristic of attractors, abrupt transitions between two network states, has been shown to occur in the CA1 subregion, but the underlying computations are thought to not occur in the hippocampal cell population that does not have recurrent connections (Wills et al. 2005). Even though similar dynamics can also be seen in the CA3 network in a corresponding behavioral paradigm (Leutgeb et al. 2006a), this does not directly reveal that the corresponding process originates there. Attractor dynamics could, like the spatial selectivity of hippocampal cells, emerge in parallel from direct projections of the medial entorhinal cortex to each hippocampal subregion.

In support of the absence of discrete attractor states within the hippocampus, CA3 cells show a strikingly linear response to intermediate sensory cue configurations when presented in conditions that provide a constant spatial input (Fig. 1C,D) (Leutgeb et al. 2005a, 2007). Pattern completion for the different cue configurations occurred only to correct for very small differences in sensory inputs and, to a somewhat larger degree, when the intermediate shapes were not familiar. While showing an approximately linear rate response to intermediate cue configurations, it is important to note that the firing locations of hippocampal cells remained constant in all three hippocampal subregions. These data are therefore consistent with the finding that pattern completion in CA3 occurs mostly as a consequence of the cells remaining bound to a currently used coordinate system and that pattern separation is strongest at two different locations (Lee et al. 2004b; Leutgeb et al. 2004, 2005b). By remaining strongly bound to a spatial map upstream of the hippocampus (Hafting et al. 2005; McNaughton et al. 2006; Fyhn et al. 2007), the CA3 network can set up a two-dimensional map in which pattern completion and pattern separation can become directly dependent on using either a shared or an entirely different section of the map.

\section{Are map-based mechanisms used for the fast encoding of memories in CA3?}

Behavioral evidence supports a role of the dentate gyrus and CA3 (Stubley-Weatherly et al. 1996; Daumas et al. 2004, 2005; Lee and Kesner 2004a) and, in particular, synaptic plasticity in the dentate gyrus (McHugh et al. 2007) in the fast acquisition of context conditioning, suggesting that there may be specialized mechanisms for rapidly storing memories in these parts of the hippocampal circuitry. Further behavioral evidence suggests that CA3 is also critically involved in rapid learning in several other tasks (Lee and Kesner 2003, 2004b; Nakazawa et al. 2003; Lee et al. 2005). In combination with evidence that the hippocampus 
is required to rapidly discriminate between similar boxes (Frankland et al. 1998; McHugh et al. 2007), this suggests that the new neuronal codes should not only emerge rapidly, but also become rapidly associated with the detailed configuration of all available sensory cues.

The immediate appearance of a new hippocampal representation in response to novelty and its persistence during later recording sessions have been considered as one of the benchmarks for a role of hippocampus in rapid memory formation (Hill 1978; O'Keefe and Speakman 1987; Thompson and Best 1990; Wilson and McNaughton 1993; Nakazawa et al. 2004). When animals are brought from a familiar environment to novel environments, the place code in CA1 appears to undergo immediate global remapping (Muller and Kubie 1987; Kentros et al. 1998; Anderson and Jeffery 2003; Wills et al. 2005). New location-selective firing patterns in CA1 are stable within minutes after the rats are introduced to a novel environment (Wilson and McNaughton 1993; Frank et al. 2004; Leutgeb et al. 2004), and they can persist for as long as place cell recordings are feasible (Thompson and Best 1990). Although distinct place cells appear rapidly in CA1, their firing patterns often initially do not discriminate between more detailed differences between recording arenas that are presented at the same location (Bostock et al. 1991; Lever et al. 2002; Leutgeb et al. 2006b). These data indicate that the CA1 cell population rapidly generates new codes for a new location, but without simultaneously encoding more detailed information about the new places.

Along with new CA1 firing after the animal begins to explore an arena, many CA3 cells also begin to immediately fire with spatial selectivity. In contrast to the stable firing in CA1 after several minutes, the emerging $\mathrm{CA} 3$ place fields continue to change for $\sim 10-20 \mathrm{~min}$ with some fields completely disappearing and others newly emerging (see Fig. 3 in Leutgeb et al. 2004). The rationale for this prolonged adjustment in CA3 is not known, but one possibility is that it is related to iteratively searching for a subpopulation of cells that is completely unrelated to those that have been used in other places (Leutgeb et al. 2004). The different time course for generating place fields in the two hippocampal cell populations not only suggests that the fast component in the CA1 cell response is, at least in part, independent of the inputs from CA3 and may therefore more directly depend on inputs from the spatial map in the medial entorhinal cortex (Brun et al. 2002; Nakazawa et al. 2003; Fyhn et al. 2004; Hafting et al. 2005), but also questions whether CA3 cell ensembles can store memories with a time course that supports fast behavioral learning.

If CA1 cells form maps that initially do not discriminate between contexts and if CA3 cells form a stable map for a new location with a delayed time course, is there a fast hipppocampal mechanism to encode new information? Few studies have specifically investigated early responses of location-selective cells in memory tasks. Early learning-related responses of locationselective cells can easily be confounded by the behavioral changes that occur at the same time. These influences of behavior have been minimized in a study by Moita et al. (2004) that showed partial remapping of CA1 place cells $1 \mathrm{~h}$ after context conditioning. The rather slow time course of remapping in CA1 may therefore be overcome when the differences between the boxes are of significance to the animals. Although it is not known whether a corresponding change would occur in CA3, it will be important to extend these studies to CA3. Despite the slow formation of CA3 fields at a new spatial location, CA3 cells can show rapid rate changes in response to changed sensory cues, which can already take place before new CA3 fields have completely stabilized (Leutgeb et al. 2006b). In contrast, the rate response of CA1 cells to the same manipulation is initially more limited and variable. The fast and reliable encoding of new sen- sory cues in CA3 suggests that the association of new information with place fields can even occur during the 20-min interval when the cells continue to settle into a new spatial firing pattern and suggests that these parallel adjustments are at least partially independent processes (Leutgeb et al. 2006b). Another example of the fast response of CA3 fields to reconfigured cue constellations is the occurrence of only a single center-of-mass shift of CA3 place fields after cue rotations on a circular track. When distal and proximal cues are first rotated out of their standard alignment, the firing locations of CA3 cells drift backward for a few laps and then remain unaltered during the remainder of the first recording session as well as on all subsequent trials with cue misalignment. In contrast, CA1 cells show backward adjustments only from the second day on (Lee et al. 2004a).

These results also show that CA3 fields more quickly reestablish a fixed spatial firing pattern after cue manipulations and that CA1 cells may always remain less strictly bound to the current sensory input. Such differences between CA3 and CA1 in responding to a change in the sensory cues are also expressed after the animals have become highly familiar with different box configurations (Fig. 3). CA3 cells return immediately to the firing pattern that is appropriate for the current configuration, while the CA1 cells are never strictly bound to the sensory inputs but

\section{A}

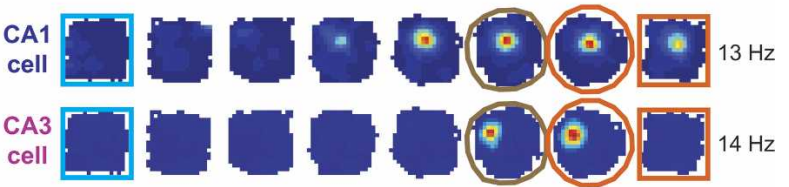

B
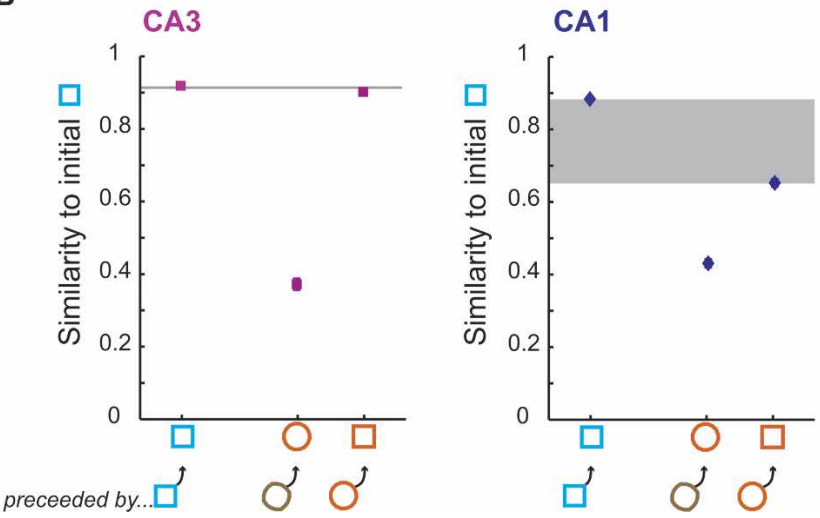

Figure 3. $C A 3$ is more strictly bound to current sensory input than CA1. Cell populations were recorded in a box with flexible walls, which was presented in seven different shapes, beginning with a square and ending with a circle. Immediately following the circle, the square was presented for a second time. (A) Color-coded rate maps are shown for two simultaneously recorded cells, one from CA1 and one from CA3. The rate maps were scaled to the maximum firing rate within the entire testing sequence $(13 \mathrm{~Hz}$ and $14 \mathrm{~Hz}$, as indicated to the right). After the direct transition from circle to square, the CA1 cell continued to show the firing pattern that was reminiscent of the circle (cf. the final square with the preceding circle), whereas the CA3 cell returned immediately to the firing pattern that was previously observed with the same spatial configuration. (B) These differences are also seen in the population activity of the recorded cells $(n=7$ rats; data reproduced from Leutgeb et al. 2005a). The three data points of each plot indicate the similarity in firing (i.e., population vector correlation) after direct repetitions of the same box shape (left), the difference between the circle and square (center), and the level of similarity when one shape is presented directly after the other (right). CA3 cell populations fully revert to the firing pattern that is appropriate for the shape, while CA1 cell populations do not respond immediately (indicated in gray). 
rather retain information about the temporal sequence in which the sensory information was presented (Fig. 3B; Leutgeb et al. 2005a). These different responses of each of the subregions in the spatial and temporal domain may extend to several related findings. First, the CA3 region is particularly important during route finding. By remaining tightly bound to spatial coordinates as well as the associated sensory cues, it may better support the generation of a path toward a goal location (Brun et al. 2002; Nakazawa et al. 2002). In contrast, the larger independence of CA1 cells from space may allow it to more efficiently encode for temporal task parameters, such as sequences and task phases (Dragoi and Buzsaki 2006; Griffin et al. 2007). Although it is currently not clear how CA1 could sustain temporal information without recurrent connectivity and when the inputs of CA3 have reverted to encoding the current space, it would have to depend either on cellular and network mechanisms within CA1 or on direct projections from the entorhinal cortex.

In contrast, when rate remapping is expressed in CA3 but not yet in CA1, it can be assumed that information about stimulus differences emerges either as a result of intrinsic hippocampal computations or as a consequence of differences between the direct entorhinal inputs to each of the hippocampal subregions. Understanding how the rapid encoding of new information emerges in CA3 in advance of CA1 thus requires a better understanding of the differences in inputs from the entorhinal cortex as well as of dentate function. For example, an important role of the dentate in contributing to rate coding in CA3 is suggested by more pronounced rate changes in the dentate cell population when differences between sensory cues are small (Leutgeb et al. 2007) and by a critical role of NMDA receptors in dentate granule cells for rapidly generating rate differences in CA3 cells (McHugh et al. 2007).

\section{Conclusions}

The fast encoding of hippocampal-dependent memories in humans and animals requires that cellular processes in the hippocampus result in an immediately stored memory trace. The rapid rate modulation of CA3 at fixed spatial coordinates is consistent with behavioral data that find a role for the dentate-CA3 network in the rapid encoding of new contextual memories (StubleyWeatherly et al. 1996; Daumas et al. 2004, 2005; Lee and Kesner 2004a; McHugh et al. 2007), for spatial working memory (McNaughton et al. 1989; Lee and Kesner 2002, 2003; Niewoehner et al. 2007), in paired associations with space (Gilbert and Kesner 2003), and in spatial pattern separation (Gilbert et al. 2001). By binding new sensory stimuli to a single, currently active coordinate system, the cell population can support the encoding of new sensory cues at a certain location or, if the animal is moving, at a sequence of locations. In addition, by using a gradual rate change to extrapolate from known sensory information, the relation to information that was previously learned in the same place is retained. Such rapid mapping of new information into a fixed coordinate system has many of the properties that would be expected from a network that supports the fast encoding and storage of memories, and it will be important to find for which memory demands this mechanism can be successfully used. Although recent data are consistent with the proposal that hippocampal rate coding makes an important contribution to encoding in memory tasks (e.g., Wood et al. 2000; Ferbinteanu and Shapiro 2003; Moita et al. 2004; Bower et al. 2005), it remains to be tested more explicitly whether the location-independent coding properties of hippocampal place cells are set aside for this function.

Compared to the information that is available for the CA1 subregions, the studies that specifically investigate the mecha- nisms of spatial and memory coding in CA3 remain small. The available evidence shows properties of CA3 cells that are consistent with functions of the area that have been seen in behavioral studies, such as preferred associations with spatial locations, a role in the rapid encoding of differences at a single location, and the reliable recall of exact sensory configurations. The data also suggest that the association with a spatial map is fundamental in CA3 and that its use of sparsely distributed firing fields can result in the binding of arbitrary information to space, in very much the same way as suggested by O'Keefe and Nadel (1978) for a cognitive map. The absence of recurrent connections downstream from CA3 seems to allow for the addition of information (e.g., nonspatial associations, sequence, time) (Eichenbaum et al. 1999; Manns and Eichenbaum 2005; Rolls and Kesner 2006) for which the spatial map is not sufficiently versatile although the underlying spatial structure may remain partially preserved and can probably be recovered in the output returning to the parahippocampal cortices. Although the question remains why a system that performs several essentially nonspatial functions would need to be tied by such a large extent to place representations, the finding that the CA3 area efficiently preserves the spatial matrix to which arbitrary items can be attached rapidly (Leutgeb et al. 2006b; Rolls and Kesner 2006; McHugh et al. 2007) may be part of the answer. This mechanism not only assigns a distinct code to each path along a sequence of locations, but also provides different output when the path is retraced after part of the contextual information has changed. In contrast to a coding scheme that relies on relocating firing fields to also encode nonspatial differences, the output from this coding scheme is informative about the path itself as well as the items that are distinctive along the way. CA3 cell ensembles may thus support the fast acquisition of detailed memories by providing locally continuous, but globally orthogonal representations, which can rapidly provide new neuronal indices when information is encountered for the first time.

\section{Acknowledgments}

We thank A. Treves, B. McNaughton, and M. Witter for their helpful comments. The work was supported by a Centre of Excellence and a NevroNor grant from the Norwegian Research Council.

\section{References}

Amaral, D.G. and Kurz, J. 1985. An analysis of the origins of the cholinergic and noncholinergic septal projections to the hippocampal formation of the rat. J. Comp. Neurol. 240: 37-59.

Amaral, D.G., Ishizuka, N., and Claiborne, B. 1990. Neurons, numbers and the hippocampal network. Prog. Brain Res. 83: 1-11.

Amit, D.J. 1989. Modeling brain function. Cambridge University Press, Cambridge, UK.

Anderson, M.I. and Jeffery, K.J. 2003. Heterogeneous modulation of place cell firing by changes in context. J. Neurosci. 23: 8827-8835.

Anderson, M.I., Killing, S., Morris, C., O’Donoghue, A., Onyiagha, D., Stevenson, R., Verriotis, M., and Jeffery, K.J. 2006. Behavioral correlates of the distributed coding of spatial context. Hippocampus 16: $730-742$.

Barnes, C.A., McNaughton, B.L., Mizumori, S.J., Leonard, B.W., and Lin, L.H. 1990. Comparison of spatial and temporal characteristics of neuronal activity in sequential stages of hippocampal processing. Prog. Brain Res. 83: 287-300.

Barnes, C.A., Suster, M.S., Shen, J., and McNaughton, B.L. 1997. Multistability of cognitive maps in the hippocampus of old rats. Nature 388: 272-275

Barry, C., Hayman, R., Burgess, N., and Jeffery, K.J. 2007. Experience-dependent rescaling of entorhinal grids. Nat. Neurosci. 10: $682-684$.

Battaglia, F.P. and Treves, A. 1998. Attractor neural networks storing multiple space representations: A model for hippocampal place fields. Phys. Rev. E 58: 7738-7753.

Battaglia, F.P., Sutherland, G.R., and McNaughton, B.L. 2004. Local sensory cues and place cell directionality: Additional evidence of 
prospective coding in the hippocampus. J. Neurosci. 24: 4541-4550.

Berger, T.W. and Thompson, R.F. 1978. Neuronal plasticity in the limbic system during classical conditioning of the rabbit nictitating membrane response. I. The hippocampus. Brain Res. 145: 323-346.

Berger, T.W., Alger, B., and Thompson, R.F. 1976. Neuronal substrate of classical conditioning in the hippocampus. Science 192: 483-485.

Best, P.J. and Ranck Jr., J.B. 1982. Reliability of the relationship between hippocampal unit activity and sensory-behavioral events in the rat. Exp. Neurol. 75: 652-664.

Blumenfeld, B., Preminger, S., Sagi, D., and Tsodyks, M. 2006. Dynamics of memory representations in networks with novelty-facilitated synaptic plasticity. Neuron 52: 383-394.

Bostock, E., Muller, R.U., and Kubie, J.L. 1991. Experience-dependent modifications of hippocampal place cell firing. Hippocampus 1: 193-205.

Bower, M.R., Euston, D.R., and McNaughton, B.L. 2005. Sequential-context-dependent hippocampal activity is not necessary to learn sequences with repeated elements. J. Neurosci. 25: $1313-1323$.

Brun, V.H., Otnass, M.K., Molden, S., Steffenach, H.A., Witter, M.P., Moser, M.B., and Moser, E.I. 2002. Place cells and place recognition maintained by direct entorhinal-hippocampal circuitry. Science 296: $2243-2246$

Brunel, N. and Trullier, O. 1998. Plasticity of directional place fields in a model of rodent CA3. Hippocampus 8: 651-665.

Buzsaki, G. 2005. Theta rhythm of navigation: Link between path integration and landmark navigation, episodic and semantic memory. Hippocampus 15: 827-840.

Buzsaki, G., Leung, L.W., and Vanderwolf, C.H. 1983. Cellular bases of hippocampal EEG in the behaving rat. Brain Res. 287: 139-171.

Colby, C.L. and Goldberg, M.E. 1999. Space and attention in parietal cortex. Annu. Rev. Neurosci. 22: 319-349.

Collins, D.R. and Pare, D. 2000. Differential fear conditioning induces reciprocal changes in the sensory responses of lateral amygdala neurons to the $\mathrm{CS}^{+}$and $\mathrm{CS}^{-}$. Learn. Mem. 7: 97-103.

Csicsvari, J., Hirase, H., Mamiya, A., and Buzsaki, G. 2000. Ensemble patterns of hippocampal CA3-CA1 neurons during sharp wave-associated population events. Neuron 28: 585-594.

Daumas, S., Halley, H., and Lassalle, J.M. 2004. Disruption of hippocampal CA3 network: Effects on episodic-like memory processing in C57BL/6J mice. Eur. J. Neurosci. 20: 597-600.

Daumas, S., Halley, H., Frances, B., and Lassalle, J.M. 2005. Encoding, consolidation, and retrieval of contextual memory: Differential involvement of dorsal CA3 and CA1 hippocampal subregions. Learn. Mem. 12: 375-382.

Dragoi, G. and Buzsaki, G. 2006. Temporal encoding of place sequences by hippocampal cell assemblies. Neuron 50: 145-157.

Dudchenko, P.A. and Zinyuk, L.E. 2005. The formation of cognitive maps of adjacent environments: Evidence from the head direction cell system. Behav. Neurosci. 119: 1511-1523.

Eichenbaum, H., Kuperstein, M., Fagan, A., and Nagode, J. 1987. Cue-sampling and goal-approach correlates of hippocampal unit activity in rats performing an odor-discrimination task. J. Neurosci. 7: 716-732.

Eichenbaum, H., Dudchenko, P., Wood, E., Shapiro, M., and Tanila, H. 1999. The hippocampus, memory, and place cells: Is it spatial memory or a memory space? Neuron 23: 209-226.

Felleman, D.J. and Van Essen, D.C. 1991. Distributed hierarchical processing in the primate cerebral cortex. Cereb. Cortex 1: 1-47.

Fenton, A.A., Csizmadia, G., and Muller, R.U. 2000. Conjoint control of hippocampal place cell firing by two visual stimuli. I. The effects of moving the stimuli on firing field positions. J. Gen. Physiol. 116: $191-209$.

Ferbinteanu, J. and Shapiro, M.L. 2003. Prospective and retrospective memory coding in the hippocampus. Neuron 40: 1227-1239.

Frank, L.M., Stanley, G.B., and Brown, E.N. 2004. Hippocampal plasticity across multiple days of exposure to novel environments. $J$. Neurosci. 24: 7681-7689.

Frankland, P.W., Cestari, V., Filipkowski, R.K., McDonald, R.J., and Silva, A.J. 1998. The dorsal hippocampus is essential for context discrimination but not for contextual conditioning. Behav. Neurosci. 112: $863-874$.

Freedman, D.J., Riesenhuber, M., Poggio, T., and Miller, E.K. 2003. A comparison of primate prefrontal and inferior temporal cortices during visual categorization. J. Neurosci. 23: 5235-5246.

Fuhs, M.C. and Touretzky, D.S. 2006. A spin glass model of path integration in rat medial entorhinal cortex. J. Neurosci. 26: $4266-4276$.

Fyhn, M., Molden, S., Hollup, S., Moser, M.B., and Moser, E. 2002. Hippocampal neurons responding to first-time dislocation of a target object. Neuron 35: 555-566.

Fyhn, M., Molden, S., Witter, M.P., Moser, E.I., and Moser, M.B. 2004.
Spatial representation in the entorhinal cortex. Science 305: $1258-1264$.

Fyhn, M., Hafting, T., Treves, A., Moser, M.B., and Moser, E.I. 2007. Hippocampal remapping and grid realignment in entorhinal cortex. Nature 446: 190-194.

Gilbert, P.E. and Kesner, R.P. 2003. Localization of function within the dorsal hippocampus: The role of the CA3 subregion in paired-associate learning. Behav. Neurosci. 117: 1385-1394.

Gilbert, P.E., Kesner, R.P., and Lee, I. 2001. Dissociating hippocampal subregions: Double dissociation between dentate gyrus and CA1. Hippocampus 11: 626-636.

Gothard, K.M., Skaggs, W.E., and McNaughton, B.L. 1996a. Dynamics of mismatch correction in the hippocampal ensemble code for space: Interaction between path integration and environmental cues. $J$. Neurosci. 16: 8027-8040.

Gothard, K.M., Skaggs, W.E., Moore, K.M., and McNaughton, B.L. 1996b. Binding of hippocampal CA1 neural activity to multiple reference frames in a landmark-based navigation task. J. Neurosci. 16: $823-835$.

Gothard, K.M., Hoffman, K.L., Battaglia, F.P., and McNaughton, B.L. 2001. Dentate gyrus and CA1 ensemble activity during spatial reference frame shifts in the presence and absence of visual input. $J$. Neurosci. 21: 7284-7292.

Griffin, A.L., Eichenbaum, H., and Hasselmo, M.E. 2007. Spatial representations of hippocampal CA1 neurons are modulated by behavioral context in a hippocampus-dependent memory task. $J$. Neurosci. 27: 2416-2423.

Hafting, T., Fyhn, M., Molden, S., Moser, M.B., and Moser, E.I. 2005. Microstructure of a spatial map in the entorhinal cortex. Nature 436: 801-806.

Hahn, T.T., Sakmann, B., and Mehta, M.R. 2007. Differential responses of hippocampal subfields to cortical up-down states. Proc. Natl. Acad. Sci. 104: 5169-5174.

Hampson, R.E., Heyser, C.J., and Deadwyler, S.A. 1993. Hippocampal cell firing correlates of delayed-match-to-sample performance in the rat. Behav. Neurosci. 107: 715-739.

Hampson, R.E., Simeral, J.D., and Deadwyler, S.A. 1999. Distribution of spatial and nonspatial information in dorsal hippocampus. Nature 402: 610-614.

Hargreaves, E.L., Yoganarasimha, D., and Knierim, J.J. 2007. Cohesiveness of spatial and directional representations recorded from neural ensembles in the anterior thalamus, parasubiculum, medial entorhinal cortex, and hippocampus. Hippocampus 17: 826-841.

Hayman, R.M., Chakraborty, S., Anderson, M.I., and Jeffery, K.J. 2003. Context-specific acquisition of location discrimination by hippocampal place cells. Eur. J. Neurosci. 18: 2825-2834.

Hill, A.J. 1978. First occurrence of hippocampal spatial firing in a new environment. Exp. Neurol. 62: 282-297.

Hollup, S.A., Molden, S., Donnett, J.G., Moser, M.B., and Moser, E.I. 2001. Accumulation of hippocampal place fields at the goal location in an annular watermaze task. J. Neurosci. 21: 1635-1644.

Isomura, Y., Sirota, A., Ozen, S., Montgomery, S., Mizuseki, K., Henze, D.A., and Buzsaki, G. 2006. Integration and segregation of activity in entorhinal-hippocampal subregions by neocortical slow oscillations. Neuron 52: 871-882.

Jeffery, K.J. 1998. Learning of landmark stability and instability by hippocampal place cells. Neuropharmacology 37: 677-687.

Jeffery, K.J., Gilbert, A., Burton, S., and Strudwick, A. 2003. Preserved performance in a hippocampal-dependent spatial task despite complete place cell remapping. Hippocampus 13: 175-189.

Kali, S. and Dayan, P. 2000. The involvement of recurrent connections in area CA3 in establishing the properties of place fields: A model. $J$. Neurosci. 20: 7463-7477.

Kentros, C., Hargreaves, E., Hawkins, R.D., Kandel, E.R., Shapiro, M., and Muller, R.V. 1998. Abolition of long-term stability of new hippocampal place cell maps by NMDA receptor blockade. Science 280: 2121-2126.

Knierim, J.J. 2002. Dynamic interactions between local surface cues, distal landmarks, and intrinsic circuitry in hippocampal place cells J. Neurosci. 22: 6254-6264.

Knierim, J.J. 2004. How to avoid going bump in the night: Object and place representations in the hippocampus. J. Gen. Physiol. 124: 3-6.

Knierim, J.J., Kudrimoti, H.S., and McNaughton, B.L. 1995. Place cells, head direction cells, and the learning of landmark stability. J. Neurosci. 15: 1648-1659.

Knierim, J.J., Kudrimoti, H.S., and McNaughton, B.L. 1998. Interactions between idiothetic cues and external landmarks in the control of place cells and head direction cells. J. Neurophysiol. 80: 425-446.

Lee, I. and Kesner, R.P. 2002. Differential contribution of NMDA receptors in hippocampal subregions to spatial working memory. Nat. Neurosci. 5: 162-168. 
Lee, I. and Kesner, R.P. 2003. Differential roles of dorsal hippocampal subregions in spatial working memory with short versus intermediate delay. Behav. Neurosci. 117: 1044-1053.

Lee, I. and Kesner, R.P. 2004a. Differential contributions of dorsal hippocampal subregions to memory acquisition and retrieval in contextual fear-conditioning. Hippocampus 14: 301-310.

Lee, I. and Kesner, R.P. 2004b. Encoding versus retrieval of spatial memory: Double dissociation between the dentate gyrus and the perforant path inputs into CA3 in the dorsal hippocampus. Hippocampus 14: 66-76.

Lee, I., Rao, G., and Knierim, J.J. 2004a. A double dissociation between hippocampal subfields: Differential time course of CA3 and CA1 place cells for processing changed environments. Neuron 42: $803-815$.

Lee, I., Yoganarasimha, D., Rao, G., and Knierim, J.J. 2004b. Comparison of population coherence of place cells in hippocampal subfields CA1 and CA3. Nature 430: $456-459$.

Lee, I., Hunsaker, M.R., and Kesner, R.P. 2005. The role of hippocampal subregions in detecting spatial novelty. Behav. Neurosci. 119: $145-153$.

Leutgeb, S. and Mizumori, S.J. 2002. Context-specific spatial representations by lateral septal cells. Neuroscience 112: 655-663.

Leutgeb, S., Leutgeb, J.K., Treves, A., Moser, M.B., and Moser, E.I. 2004. Distinct ensemble codes in hippocampal areas CA3 and CA1. Science 305: $1295-1298$.

Leutgeb, J.K., Leutgeb, S., Treves, A., Meyer, R., Barnes, C.A., McNaughton, B.L., Moser, M.B., and Moser, E.I. 2005a. Progressive transformation of hippocampal neuronal representations in "morphed" environments. Neuron 48: 345-358.

Leutgeb, S., Leutgeb, J.K., Barnes, C.A., Moser, E.I., McNaughton, B.L., and Moser, M.B. 2005b. Independent codes for spatial and episodic memory in hippocampal neuronal ensembles. Science 309: 619-623.

Leutgeb, S., Jezek, K., Colgin, L.L., Leutgeb, J.K., McNaughton, B.L., Moser, E.I., and Moser, M.-B. 2006a. Continuous and discontinuous representations in ensembles of hippocampal place cells. Society for Neuroscience, Washington, DC.

Leutgeb, S., Leutgeb, J.K., Moser, E.I., and Moser, M.B. 2006b. Fast rate coding in hippocampal CA3 cell ensembles. Hippocampus 16: $765-774$.

Leutgeb, J.K., Leutgeb, S., Moser, M.B., and Moser, E.I. 2007. Pattern separation in the dentate gyrus and CA3 of the hippocampus. Science 315: $961-966$

Lever, C., Wills, T., Cacucci, F., Burgess, N., and O'Keefe, J. 2002. Long-term plasticity in hippocampal place-cell representation of environmental geometry. Nature 416: 90-94.

Lipton, P.A., White, J.A., and Eichenbaum, H. 2007. Disambiguation of overlapping experiences by neurons in the medial entorhinal cortex. J. Neurosci. 27: 5787-5795.

Manns, J.R. and Eichenbaum, H. 2005. Time and treason to the trisynaptic teachings: Theoretical comment on Kesner et al. (2005). Behav. Neurosci. 119: 1140-1143.

Marr, D. 1971. Simple memory: A theory for archicortex. Philos. Trans. R. Soc. Lond. B Biol. Sci. 262: 23-81.

Maurer, A.P., Vanrhoads, S.R., Sutherland, G.R., Lipa, P., and McNaughton, B.L. 2005. Self-motion and the origin of differential spatial scaling along the septo-temporal axis of the hippocampus. Hippocampus 15: 841-852.

McEchron, M.D. and Disterhoft, J.F. 1997. Sequence of single neuron changes in CA1 hippocampus of rabbits during acquisition of trace eyeblink conditioned responses. J. Neurophysiol. 78: 1030-1044.

McHugh, T.J., Jones, M.W., Quinn, J.J., Balthasar, N., Coppari, R. Elmquist, J.K., Lowell, B.B., Fanselow, M.S., Wilson, M.A., and Tonegawa, S. 2007. Dentate gyrus NMDA receptors mediate rapid pattern separation in the hippocampal network. Science 317: 94-99.

McNaughton, B.L. and Morris, R.G.M. 1987. Hippocampal synaptic enhancement and information storage within a distributed memory system. Trends Neurosci. 10: 408-415.

McNaughton, B.L., Barnes, C.A., and O'Keefe, J. 1983. The contributions of position, direction, and velocity to single unit activity in the hippocampus of freely-moving rats. Exp. Brain Res. 52: 41-49.

McNaughton, B.L., Barnes, C.A., Meltzer, J., and Sutherland, R.J. 1989. Hippocampal granule cells are necessary for normal spatial learning but not for spatially-selective pyramidal cell discharge. Exp. Brain Res. 76: $485-496$.

McNaughton, B.L., Barnes, C.A., Gerrard, J.L., Gothard, K., Jung, M.W. Knierim, J.J., Kudrimoti, H., Qin, Y., Skaggs, W.E., Suster, M., et al. 1996. Deciphering the hippocampal polyglot: The hippocampus as a path integration system. J. Exp. Biol. 199: 173-185.

McNaughton, B.L., Battaglia, F.P., Jensen, O., Moser, E.I., and Moser, M.-B. 2006. Path-integration and the neural basis of the 'cognitive map.'. Nat. Rev. Neurosci. 7: 663-678.

Miller, V.M. and Best, P.J. 1980. Spatial correlates of hippocampal unit activity are altered by lesions of the fornix and endorhinal cortex. Brain Res. 194: 311-323.

Mizumori, S.J., McNaughton, B.L., Barnes, C.A., and Fox, K.B. 1989. Preserved spatial coding in hippocampal CA1 pyramidal cells during reversible suppression of CA3c output: Evidence for pattern completion in hippocampus. J. Neurosci. 9: 3915-3928.

Moita, M.A., Rosis, S., Zhou, Y., LeDoux, J.E., and Blair, H.T. 2003. Hippocampal place cells acquire location-specific responses to the conditioned stimulus during auditory fear conditioning. Neuron 37: 485-497.

Moita, M.A., Rosis, S., Zhou, Y., LeDoux, J.E., and Blair, H.T. 2004. Putting fear in its place: Remapping of hippocampal place cells during fear conditioning. J. Neurosci. 24: 7015-7023.

Muller, R.U. and Kubie, J.L. 1987. The effects of changes in the environment on the spatial firing of hippocampal complex-spike cells. J. Neurosci. 7: 1951-1968.

Muller, R.U., Kubie, J.L., and Ranck Jr., J.B. 1987. Spatial firing patterns of hippocampal complex-spike cells in a fixed environment. $J$. Neurosci. 7: 1935-1950.

Muller, R.U., Bostock, E., Taube, J.S., and Kubie, J.L. 1994. On the directional firing properties of hippocampal place cells. J. Neurosci. 14: $7235-7251$.

Munera, A., Gruart, A., Munoz, M.D., Fernandez-Mas, R., and Delgado-Garcia, J.M. 2001. Hippocampal pyramidal cell activity encodes conditioned stimulus predictive value during classical conditioning in alert cats. J. Neurophysiol. 86: 2571-2582.

Nakazawa, K., Quirk, M.C., Chitwood, R.A., Watanabe, M., Yeckel, M.F., Sun, L.D., Kato, A., Carr, C.A., Johnston, D., Wilson, M.A., et al. 2002. Requirement for hippocampal CA3 NMDA receptors in associative memory recall. Science 297: 211-218.

Nakazawa, K., Sun, L.D., Quirk, M.C., Rondi-Reig, L., Wilson, M.A., and Tonegawa, S. 2003. Hippocampal CA3 NMDA receptors are crucial for memory acquisition of one-time experience. Neuron 38: 305-315.

Nakazawa, K., McHugh, T.J., Wilson, M.A., and Tonegawa, S. 2004. NMDA receptors, place cells and hippocampal spatial memory. Nat. Rev. Neurosci. 5: 361-372.

Niewoehner, B., Single, F.N., Hvalby, O., Jensen, V., Borgloh, S.M., Seeburg, P.H., Rawlins, J.N., Sprengel, R., and Bannerman, D.M 2007. Impaired spatial working memory but spared spatial reference memory following functional loss of NMDA receptors in the dentate gyrus. Eur. J. Neurosci. 25: 837-846.

O'Keefe, J. 1976. Place units in the hippocampus of the freely moving rat. Exp. Neurol. 51: 78-109.

O'Keefe, J. and Burgess, N. 1996. Geometric determinants of the place fields of hippocampal neurons. Nature 381: 425-428.

O'Keefe, J. and Conway, D.H. 1978. Hippocampal place units in the freely moving rat: Why they fire where they fire. Exp. Brain Res. 31: $573-590$.

O'Keefe, J. and Dostrovsky, J. 1971. The hippocampus as a spatial map. Preliminary evidence from unit activity in the freely-moving rat. Brain Res. 34: 171-175.

O'Keefe, J. and Nadel, L. 1978. The hippocampus as a cognitive map. Oxford University Press, Oxford.

O'Keefe, J. and Speakman, A. 1987. Single unit activity in the rat hippocampus during a spatial memory task. Exp. Brain Res. 68: 1-27.

Olds, J., Disterhoft, J.F., Segal, M., Kornblith, C.L., and Hirsh, R. 1972. Learning centers of the brain mapped by measuring latencies of conditioned unit responses. J. Neurophysiol. 35: 202-219.

Olton, D.S., Branch, M., and Best, P.J. 1978. Spatial correlates of hippocampal unit activity. Exp. Neurol. 58: 387-409.

Otto, T. and Eichenbaum, H. 1992. Neuronal activity in the hippocampus during delayed non-match to sample performance in rats: Evidence for hippocampal processing in recognition memory. Hippocampus 2: 323-334.

Paz-Villagran, V., Save, E., and Poucet, B. 2004. Independent coding of connected environments by place cells. Eur. J. Neurosci. 20: $1379-1390$

Paz-Villagran, V., Save, E., and Poucet, B. 2006. Spatial discrimination of visually similar environments by hippocampal place cells in the presence of remote recalibrating landmarks. Eur. J. Neurosci. 23: $187-195$.

Quirk, G.J., Muller, R.U., and Kubie, J.L. 1990. The firing of hippocampal place cells in the dark depends on the rat's recent experience. J. Neurosci. 10: 2008-2017.

Quirk, G.J., Muller, R.U., Kubie, J.L., and Ranck Jr., J.B. 1992. The positional firing properties of medial entorhinal neurons: Description and comparison with hippocampal place cells. $J$. Neurosci. 12: 1945-1963.

Quirk, G.J., Repa, C., and LeDoux, J.E. 1995. Fear conditioning enhances short-latency auditory responses of lateral amygdala neurons: Parallel recordings in the freely behaving rat. Neuron 15: 1029-1039.

Ranck Jr., J.B. 1973. Studies on single neurons in dorsal hippocampal 
formation and septum in unrestrained rats. I. Behavioral correlates and firing repertoires. Exp. Neurol. 41: 461-531.

Rapp, P.R. 1998. Representational organization in the aged hippocampus. Hippocampus 8: 432-435.

Renaudineau, S., Poucet, B., and Save, E. 2007. Flexible use of proximal objects and distal cues by hippocampal place cells. Hippocampus 17: 381-395.

Repa, J.C., Muller, J., Apergis, J., Desrochers, T.M., Zhou, Y., and LeDoux, J.E. 2001. Two different lateral amygdala cell populations contribute to the initiation and storage of memory. Nat. Neurosci. 4: 724-731.

Rolls, E.T. 1989. Functions of neuronal networks in the hippocampus and cerebral cortex in memory. In Models of brain function (ed. R. Cotterill), pp. 15-33. Cambridge University Press, Cambridge, UK.

Rolls, E.T. and Kesner, R.P. 2006. A computational theory of hippocampal function, and empirical tests of the theory. Prog Neurobiol. 79: 1-48.

Rolls, E.T., Stringer, S.M., and Elliot, T. 2006. Entorhinal cortex grid cells can map to hippocampal place cells by competitive learning. Network 17: 447-465.

Samsonovich, A. and McNaughton, B.L. 1997. Path integration and cognitive mapping in a continuous attractor neural network model. J. Neurosci. 17: 5900-5920.

Sargolini, F., Fyhn, M., Hafting, T., McNaughton, B.L., Witter, M.P., Moser, M.B., and Moser, E.I. 2006. Conjunctive representation of position, direction, and velocity in entorhinal cortex. Science 312: $758-762$.

Segal, M. and Olds, J. 1972. Behavior of units in hippocampal circuit of the rat during learning. J. Neurophysiol. 35: 680-690.

Segal, M., Disterhoft, J.F., and Olds, J. 1972. Hippocampal unit activity during classical aversive and appetitive conditioning. Science 175: 792-794.

Shapiro, M.L., Tanila, H., and Eichenbaum, H. 1997. Cues that hippocampal place cells encode: Dynamic and hierarchical representation of local and distal stimuli. Hippocampus 7: 624-642.

Sik, A., Ylinen, A., Penttonen, M., and Buzsaki, G. 1994. Inhibitory CA1-CA3-hilar region feedback in the hippocampus. Science 265: $1722-1724$.

Skaggs, W.E. and McNaughton, B.L. 1998. Spatial firing properties of hippocampal CA1 populations in an environment containing two visually identical regions. J. Neurosci. 18: 8455-8466.

Skaggs, W.E., Knierim, J.J., Kudrimoti, H.S., and McNaughton, B.L. 1995. A model of the neural basis of the rat's sense of direction. Adv. Neural Inf. Process. Syst. 7: 173-180.

Smith, D.M. and Mizumori, S.J. 2006a. Learning-related development of context-specific neuronal responses to places and events: The hippocampal role in context processing. J. Neurosci. 26: 3154-3163.

Smith, D.M. and Mizumori, S.J. 2006b. Hippocampal place cells, context, and episodic memory. Hippocampus 16: 716-729.

Solstad, T., Moser, E.I., and Einevoll, G.T. 2006. From grid cells to place cells: A mathematical model. Hippocampus 16: 1026-1031.

Stolar, N., Sparenborg, S., Donchin, E., and Gabriel, M. 1989. Conditional stimulus probability and activity of hippocampal cingulate cortical, and limbic thalamic neurons during avoidance conditioning in rabbits. Behav. Neurosci. 103: 919-934.

Stubley-Weatherly, L., Harding, J.W., and Wright, J.W. 1996. Effects of discrete kainic acid-induced hippocampal lesions on spatial and contextual learning and memory in rats. Brain Res. 716: 29-38.

Tanila, H. 1999. Hippocampal place cells can develop distinct representations of two visually identical environments. Hippocampus 9: 235-246.

Tanila, H., Shapiro, M.L., and Eichenbaum, H. 1997. Discordance of spatial representation in ensembles of hippocampal place cells.
Hippocampus 7: 613-623.

Taube, J.S., Muller, R.U., and Ranck Jr., J.B. 1990. Head-direction cells recorded from the postsubiculum in freely moving rats. II. Effects of environmental manipulations. J. Neurosci. 10: 436-447.

Thompson, L.T. and Best, P.J. 1990. Long-term stability of the place-field activity of single units recorded from the dorsal hippocampus of freely behaving rats. Brain Res. 509: 299-308.

Treves, A. and Rolls, E.T. 1991. What determines the capacity of autoassociative memories in the brain? Network Comput. Neural Syst. 2: 371-397.

Treves, A. and Rolls, E.T. 1992. Computational constraints suggest the need for two distinct input systems to the hippocampal CA3 network. Hippocampus 2: 189-199.

Tsodyks, M. 1999. Attractor neural network models of spatial maps in hippocampus. Hippocampus 9: 481-489.

Vazdarjanova, A. and Guzowski, J.F. 2004. Differences in hippocampal neuronal population responses to modifications of an environmental context: Evidence for distinct, yet complementary, functions of CA3 and CA1 ensembles. J. Neurosci. 24: 6489-6496.

Wallenstein, G.V., Eichenbaum, H., and Hasselmo, M.E. 1998. The hippocampus as an associator of discontiguous events. Trends Neurosci. 21: 317-323.

Wills, T.J., Lever, C., Cacucci, F., Burgess, N., and O'Keefe, J. 2005. Attractor dynamics in the hippocampal representation of the local environment. Science 308: 873-876.

Wilson, M.A. and McNaughton, B.L. 1993. Dynamics of the hippocampal ensemble code for space. Science 261: 1055-1058.

Wilson, I.A., Ikonen, S., Gureviciene, I., McMahan, R.W., Gallagher, M., Eichenbaum, H., and Tanila, H. 2004. Cognitive aging and the hippocampus: How old rats represent new environments. J. Neurosci. 24: $3870-3878$.

Wilson, I.A., Ikonen, S., Gurevicius, K., McMahan, R.W., Gallagher, M., Eichenbaum, H., and Tanila, H. 2005. Place cells of aged rats in two visually identical compartments. Neurobiol. Aging 26: 1099-1106.

Witter, M.P. 2007. Intrinsic and extrinsic wiring of CA3: Indications for connectional heterogeneity. Learn. Mem. (this issue). doi: 10.1101/lm.725207.

Witter, M.P. and Amaral, D.G. 2004. Hippocampal formation. In The rat nervous system, 3d ed. (ed. G. Paxinos), pp. 637-703. Academic Press, San Diego.

Witter, M.P. and Moser, E.I. 2006. Spatial representation and the architecture of the entorhinal cortex. Trends Neurosci. 29: 671-678.

Witter, M.P., Naber, P.A., van Haeften, T., Machielsen, W.C., Rombouts, S.A., Barkhof, F., Scheltens, P., and Lopes da Silva, F.H. 2000. Cortico-hippocampal communication by way of parallel parahippocampal-subicular pathways. Hippocampus 10: 398-410.

Wood, E.R., Dudchenko, P.A., and Eichenbaum, H. 1999. The global record of memory in hippocampal neuronal activity. Nature 397: 613-616.

Wood, E.R., Dudchenko, P.A., Robitsek, R.J., and Eichenbaum, H. 2000. Hippocampal neurons encode information about different types of memory episodes occurring in the same location. Neuron 27: 623-633.

Yoganarasimha, D. and Knierim, J.J. 2005. Coupling between place cells and head direction cells during relative translations and rotations of distal landmarks. Exp. Brain Res. 160: 344-359.

Yoganarasimha, D., Yu, X., and Knierim, J.J. 2006. Head direction cell representations maintain internal coherence during conflicting proximal and distal cue rotations: Comparison with hippocampal place cells. J. Neurosci. 26: 622-631.

Received July 17, 2007; accepted in revised form September 26, 2007. 


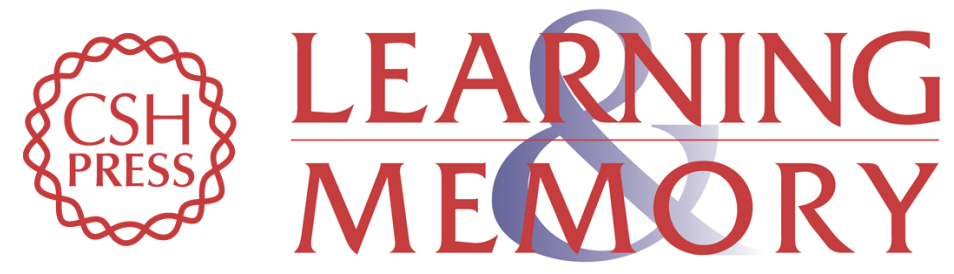

\section{Pattern separation, pattern completion, and new neuronal codes within a continuous CA3 map}

Stefan Leutgeb and Jill K. Leutgeb

Learn. Mem. 2007, 14:

Access the most recent version at doi:10.1101//m.703907

References This article cites 150 articles, 51 of which can be accessed free at: http://learnmem.cshlp.org/content/14/11/745.full.htmI\#ref-list-1

License

Email Alerting Receive free email alerts when new articles cite this article - sign up in the box at the Service top right corner of the article or click here. 